\title{
Role of percutaneous transhepatic biliary drainage in the management of blunt liver trauma: A case report
}

\author{
Şükrü Oğuz, ${ }^{1}$ M.D., Reyyan Yıldırım, ${ }^{2}$ M.D., Serdar Topaloğlu, ${ }^{2}$ M.D. \\ ${ }^{1}$ Department of Radiology, Karadeniz Technical University, Farabi Hospital, Trabzon-Turkey \\ ${ }^{2}$ Department of General Surgery, Karadeniz Technical University, Farabi Hospital, Trabzon-Turkey
}

\begin{abstract}
The liver is the most commonly injured intra-abdominal organ after blunt trauma. The management of massive liver injury is complex. Percutaneous transhepatic biliary drainage is the first approach considered, particularly for proximal bile duct strictures after liver surgery. A 27-year-old female patient was transferred to our emergency department with grade $V$ blunt injury. Regarding the patient's unresponsive hemodynamic instability, right hepatectomy was performed. The patient presented with benign biliary duct stricture after surgery that were treated via the percutaneous approach.
\end{abstract}

Keywords: Benign biliary stricture; liver injury; percutaneous approach.

\section{INTRODUCTION}

The liver is the most commonly injured intra-abdominal organ after blunt trauma. ${ }^{[1]}$ The management of massive liver injury is complex. A decision on whether the operative or non-operative approach to liver injury should be used largely depends on the experience of the management team. Biliary duct injury is rare complication encountered after hepatic surgery. ${ }^{[2]}$ Percutaneous transhepatic biliary drainage (PTBD) is the first approach considered, particularly for proximal bile duct strictures. ${ }^{[3]}$ A multidisciplinary approach is required for managing patients.

Here we present the case of a patient with massive liver trauma who was managed with surgical and interventional radiology teams.

\section{CASE REPORT}

A 27-year-old female was admitted to the emergency department with multiple traumas after a traffic accident. En-

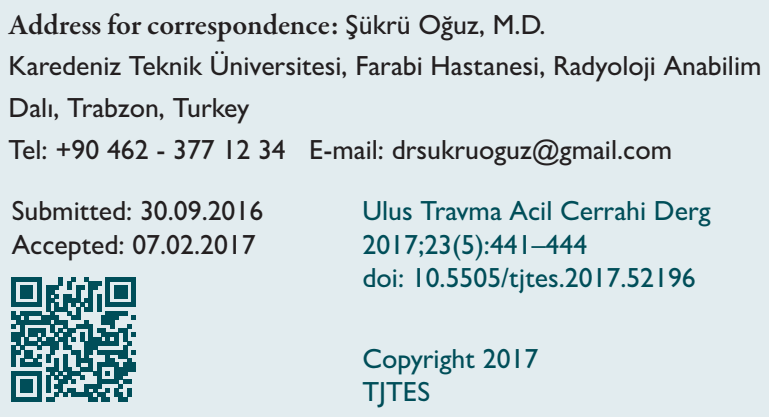

dotracheal intubation and tube drainage of the right thorax were performed at the site where the accident took place. Her past medical history was unremarkable. Her physical examination revealed resistant hypotension, tachycardia, abdominal distention, deformities on the left lower and left upper extremities, and maxillofacial trauma.

The hemoglobin level was $6 \mathrm{~g} / \mathrm{dl}$, and hematocrit was $17.8 \%$. Computed tomography (CT) in the emergency department revealed nasal fracture, multiple fractures in the right and left orbital spaces, a left mandibular fracture, a fracture in the posterior wall of left maxillary sinus, right hemothorax, and grade $V$ blunt liver injury (according to the 1994 revision of organ injury scaling by Moore et al. ${ }^{[4]}$ ), and intra-abdominal bleeding (Fig. I). Because of the patient's unresponsive hemodynamic instability, laparotomy was performed. Right hepatectomy with repair of injury of the main portal vein was required for achieving hemostasis. The stabilization of extremity fractures (a fracture in the distal part of the left femoral shaft, fracture in the left pelvic ramus, and fractures in the left forehand) was also performed in the operation. The patient received 6 units of erythrocyte suspension and 8 units of fresh frozen plasma (FFP) during the operation. Re-exploration was required $8 \mathrm{~h}$ after the initial operation because of the persistent bleeding from the abdominal drains. Hemostasis of the raw surface of the remnant liver with additional sutures was achieved during re-laparotomy. During the initial $24 \mathrm{~h}$ period after the trauma, the patient underwent massive transfusion: I I units of erythrocyte suspension, 24 units of FFP, and I unite of thrombocyte suspension. The patient was followed up under ventilation support with anti-edema medications, anti-epileptic medications, and 
ceftriaxone-metronidazole antibiotic treatment. Parenteral bicarbonate replacement was started on the third postoperative day (POD) because of the presence of myoglobinuria. Elevated the international normalized ratio (INR) $(>2)$ was observed on the fourth POD. After controlling the patency of vascular and biliary structures of the remnant liver with ultrasound, plasma exchange treatment (with 10 units of FFP per day) was started for the treatment of postoperative liver failure. Extubation was achieved on the seventh POD. Enteral feeding was started on the eighth POD. Normalization of INR was achieved with daily plasma exchange in the second postoperative week. However, increment in total and direct bilirubin levels during plasma exchange was noted. Abdominal CT on the $14^{\text {th }}$ POD revealed biliary dilatation in the remnant liver (Fig. 2a).

To decompress the biliary duct, PTBD was planned. The remnant left bile ducts were punctured using a 22-G needle via the subxiphoid approach with ultrasound guidance to perform percutaneous cholangiography (PTC). Initial percutaneous transhepatic cholangiogram revealed a high-grade Strasberg type E4 stricture of the left hepatic duct and no contrast medium passage distally. Then, an 8-F external biliary drainage catheter was placed proximal to the level of obstruction (Fig. 2b). In the second-look cholangiography two weeks later, total obstruction of the left hepatic bile duct persisted. In the third-look cholangiography on month later, passage of the minimally contrast medium distally to common hepatic duct and a niche in the most distal tip of the left hepatic duct were observed. This niche was considered as the obstruction level; therefore, an attempt was made to pass it using a standard 0.035 " hydrophilic guide wire (0.035 Radiofocus ${ }^{\circledR}$ Guidewire, Terumo Corp., Somerset, NJ, USA). Because of the failure to pass the obstruction with the standard 0.035 " hydrophilic guide wire, a microcatheter (Progreat, Terumo Corp., Somerset, NJ, USA) with its standard microwire (0.018') was used. However, this could not be passed with standard peripheral micromaterials. For this reason, this was attempted to pass obstruction using a neurointervention-dedicated microguidewire (X-Pedion-I4 (0.00I4”), Ev3 Micro Therapeutics Inc., CA, USA). The last attempt with this micro-guidewire resulted in successful passing. Finally, an 8-F internal-external biliary drainage catheter was placed.

The internal-external biliary drainage catheter was oversized to a $10 \mathrm{~F}$ catheter after one month. Because of the sustained stricture after three months of follow-up, the stricture was dilated twice using 6-8 conventional angioplasty balloon catheters at intervals of two weeks. The internal-external biliary drainage catheter was replaced by an external biliary drainage catheter, and it was closed to evaluate the success (Fig. 3). When laboratory test results and biliary passage were normal after two weeks, the external biliary drainage catheter was removed.

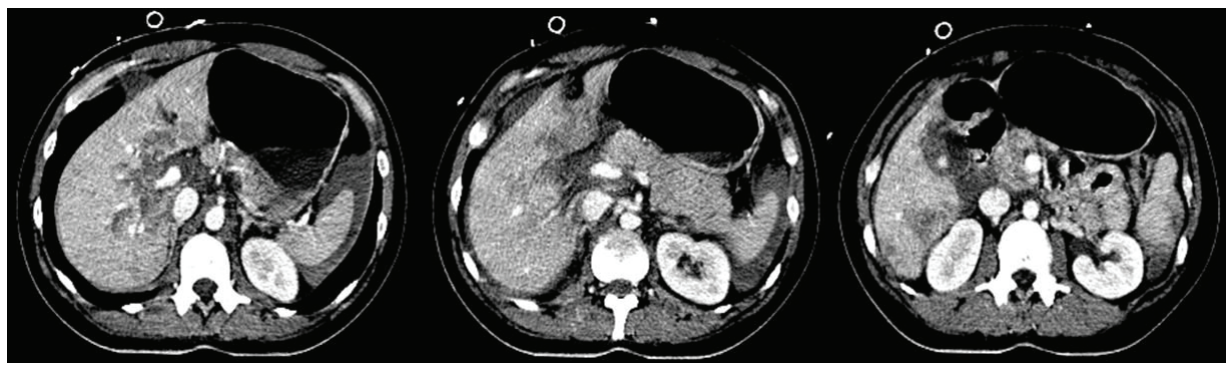

Figure 1. Axial contrast-enhanced CT images showing hypodense areas in multiple segments of the liver, indicating grade $\mathrm{V}$ liver injury.
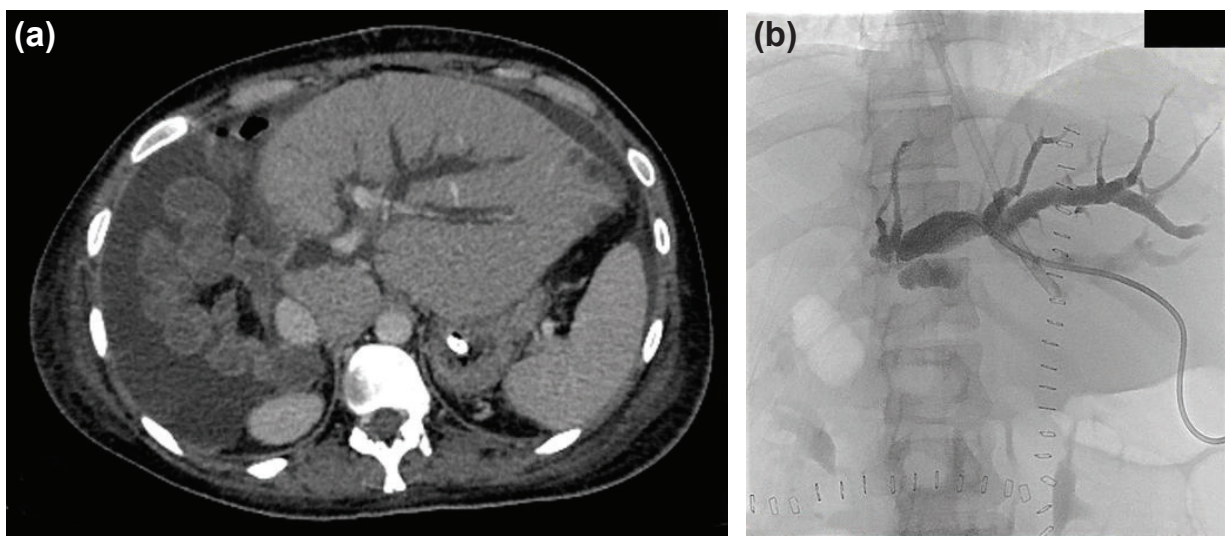

Figure 2. (a) Axial non-contrast CT image showing dilatation of the left biliary duct. (b) Initial percutaneous transhepatic cholangiogram showing a high-grade Strasberg type E4 stricture of the left hepatic duct and no contrast medium passage distally. 

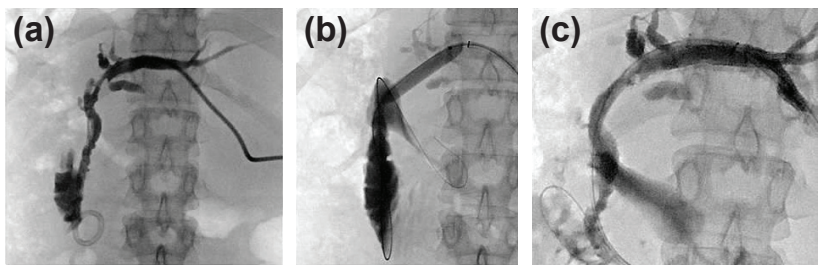

Figure 3. (a) Control percutaneous transhepatic cholangiogram showing the sustained stricture after three months. (b) A stiff guide wire was placed using an internal-external biliary drainage catheter, and the balloon was inflated at the level of the stricture. (c) The stricture was successfully dilated.

\section{DISCUSSION}

An iatrogenic bile duct structure is a rare complication that occurs after gastrointestinal surgery; its prevalence is continuously increasing. Primary causes of IBDSs are bile duct surgery such as open and laparoscopic cholecystectomy (the most common reason), choledochotomy, and previous surgery on the bile duct. Hepatic resection, liver transplantation, gastric resection, pancreatic resection and biloenteric anastomosis are rarer reasons. Direct bile duct trauma, thermal injury as a result of over-cauterization, ischemia of the bile duct secondary to vascular injury, and incorrectly placed vascular clips may cause stricture during such major surgical operations. ${ }^{[2,5-8]}$

The selective non-operative management of blunt liver trauma has become the standard of care. However, hemodynamic stability and no signs of peritonitis are absolute requirements in the non-operative management. In approximately $80 \%$ to $85 \%$ of patients undergoing operative management, the liver injury can be managed by relatively simple surgical techniques such as the application of local hemostatic agents, electrocoagulation, superficial suturing, or closed drains. ${ }^{[1]}$ The remaining $15 \%$ to $20 \%$ of cases are associated with extensive parenchymal damage not amenable to deep suturing or perihepatic packing. Non-anatomic or anatomic resection of the injured liver may be required for hemostasis or preventing subsequent necrosis and sepsis or delayed hemorrhage. In the hands of experienced hepatobiliary surgeons, liver resection for trauma is associated with acceptable morbidity and mortality rates. ${ }^{[9-11]}$

The incidence of postoperative liver-related complications in patients surviving with severe liver injuries (grade III-IV) has been reported to be nearly $50 \%{ }^{\left[{ }^{[2]}\right.}$ These complications include early or late hemorrhage, liver necrosis, liver failure, liver abscess, false aneurysms, arteriovenous fistulas, bilomas, biliary fistulas, hemobilia, and biliary strictures. ${ }^{[1,9-12]}$ Liver failure is generally transient in patients without huge liver necrosis, and liver functions are improved within 2 to 3 weeks supportive treatment, which was similar to that seen in our case. ${ }^{[13]}$ Resistant hyperbilirubinemia or biliary fistula during the early postoperative period after liver resection always indicates biliary duct obstruction. The necessity of the rapid control and ligation of hepatic inflow/outflow structures belonged to remove liver lobe is a major concern in trauma surgery in contrast to elective liver resections. Control of biliary duct patency is generally the secondary goal in patients with hemodynamic instability. Mass ligation of hilar structures may be associated with kinking of the extrahepatic biliary duct. The reported incidence of postoperative biliary complications increases with the severity of liver injury. ${ }^{[14]}$

IBDSs rare treated by surgical, endoscopic, or percutaneous approaches and non-invasive approaches are recommended as the first options. ${ }^{[2,15]}$ Although, endoscopic retrograde cholangiopancreatography (ERCP) is the first recommended treatment option, proximal bile duct strictures and gastrointestinal surgery procedures (such as Roux-en $Y$ hepaticojejunostomy), which do not permit access, are the main limiting factors. ${ }^{[6,17]}$ PTC is superior for proximal bile duct strictures and common bile duct or right aberrant hepatic bile duct injury than ERCP. ${ }^{[3]}$ The percutaneous approach is the first choice of treatment in situations the following situations: avoiding a second surgical procedure, failure of ERCP, complete ductal ligation or trans-section, proximal bile duct strictures, or requirement of immediate decompression of the biliary duct. ${ }^{[15]}$ However, there is no consensus on how benign bile strictures should be treated, including the optimal duration of biliary drainage or balloon dilatation, the size of the drainage catheter, the frequency of procedures, the size and type of balloons or the usage of stents. ${ }^{[18]}$ The optimal duration of biliary drainage is unclear, although it is more than four months associated with improved ductal patency. ${ }^{[19]}$ Technically, success is considered when there is residual stenosis of $30 \%$ or less after balloon dilatation. ${ }^{[18]}$ The biliary drainage catheter is pulled back proximal to the stricture and is closed to check the success. If a patient is asymptomatic and laboratory test results are normal in the following 7-10 days, the biliary drainage catheter is removed. Long term patency has been reported in $33-90 \%$ of cases using this technique. ${ }^{[18,20]}$

\section{Conclusion}

In case of traumatic fragile livers, the first point of PTC that needs to be considered is that the bile duct should be punctured using a 2l G or smaller needle with ultrasound guidance. The drainage catheter should be placed as gently as possible. The priority should be bile drainage, and the stricture should be attempted to be passed in later session in the event of major liver surgery or trauma. The stricture should not be forced with excessive maneuvers in fragile livers to avoid undesirable complications of PTBD. Repeat cholangiography with reasonable intervals can resolve the occlusion through hints such as passing of the contrast medium or observing a niche. Furthermore, the materials used in intravascular procedures, with the knowledge and experience gained in this area, can help in solving problems in nonvascular procedures.

Conflict of interest: None declared. 


\section{REFERENCES}

1. Demetriades D, Salim A, Berne TV. Liver and bile duct injury. In: Surgery of the liver, biliary tract, and pancreas. (Eds: L.H. Blumgart), 4th ed., Saunders, 2007.pp. 1035-48.

2. Jabłońska B, Lampe P. Iatrogenic bile duct injuries: etiology, diagnosis and management. World J Gastroenterol 2009;15:4097-104. [CrossRef]

3. Lau WY, Lai EC, Lau SH. Management of bile duct injury after laparoscopic cholecystectomy: a review. ANZ J Surg 2010;80:75-81. [CrossRef]

4. Moore EE, Cogbill TH, Jurkovich GJ, Shackford SR, Malangoni MA, Champion HR. Organ injury scaling: spleen and liver (1994 revision). J Trauma 1995 Mar;38:323-4. [CrossRef]

5. Judah JR, Draganov PV. Endoscopic therapy of benign biliary strictures. World J Gastroenterol 2007;13:3531-9. [CrossRef]

6. Ramos-De la Medina A, Misra S, Leroy AJ, Sarr MG. Management of benign biliary strictures by percutaneous interventional radiologic techniques (PIRT). HPB (Oxford) 2008;10:428-32. [CrossRef]

7. Yeo CJ, Lillemoe KD, Ahrendt SA, Pitt HA. Operative management of strictures and benign obstructive disorders of the bile duct. In: Zuidema GD, Yeo CJ, Orringer MB, editors. Shackelford's surgery of the alimentary tract, Vol 3. 5th ed. Philadelphia: W.B. Saunders Company; 2002. pp. 247-61.

8. Jarnagin WR, Blumgart LH. Benign biliary strictures. In: Blumgart LH, Fong Y, editors. Surgery of the liver and biliary tract. Philadelphia: W.B. Saunders Company; 2002. pp. 895-929.

9. Strong RW, Lynch SV, Wall DR, Liu CL. Anatomic resection for severe liver trauma. Surgery 1998;123:251-7. [CrossRef]

10. Blumgart LH, Drury JK, Wood CB. Hepatic resection for trauma, tumour and biliary obstruction. Br J Surg 1979;66:762-9. [CrossRef]
11. Kasai T, Kobayashi K. Searching for the best operative modality for severe hepatic injuries. Surg Gynecol Obstet 1993;177:551-5.

12. Demetriades D, Karaiskakis M, Alo K, Velmahos G, Murray J, Asensio J. Role of postoperative computed tomography in patients with severe liver injury. Br J Surg 2003;90:1398-400. [CrossRef]

13. Topaloğlu S, Yankol Y, Küçükkartallar T, Ocak İ, Doğruer K, Koçak B, et al. The current status of non-biologic liver support in the treatment of liver failure. Dahili ve Cerrahi Bilimler Yoğun Bakım Dergisi 2010;1:1420.

14. Hollands MJ, Little JM. Post-traumatic bile fistulae. J Trauma 1991;31:117-20. [CrossRef]

15. Krokidis M, Orgera G, Rossi M, Matteoli M, Hatzidakis A. Interventional radiology in the management of benign biliary stenoses, biliary leaks and fistulas: a pictorial review. Insights Imaging 2013;4:77-84.

16. Vitale GC, Tran TC, Davis BR, Vitale M, Vitale D, Larson G. Endoscopic management of postcholecystectomy bile duct strictures. J Am Coll Surg 2008;206:918-25. [CrossRef]

17. Thompson CM, Saad NE, Quazi RR, Darcy MD, Picus DD, Menias CO. Management of iatrogenic bile duct injuries: role of the interventional radiologist. Radiographics 2013;33:117-34. [CrossRef]

18. Saad WE. Percutaneous management of postoperative anastomotic biliary strictures. Tech Vasc Interv Radiol 2008;11:143-53. [CrossRef]

19. Misra S, Melton GB, Geschwind JF, Venbrux AC, Cameron JL, Lillemoe KD. Percutaneous management of bile duct strictures and injuries associated with laparoscopic cholecystectomy: a decade of experience. J Am Coll Surg 2004;198:218-26. [CrossRef]

20. Laasch HU, Martin DF. Management of benign biliary strictures. Cardiovasc Intervent Radiol 2002;25:457-66. [CrossRef]

\section{OLGU SUNUMU - ÖZET}

\section{Karaciğer künt travma yönetiminde perkütan biliyer drenajın rolü: Olgu sunumu Dr. Şükrü Oğuz, ${ }^{1}$ Dr. Reyyan Yıldırım, ${ }^{2}$ Dr. Serdar Topaloğlú ${ }^{2}$ \\ ${ }^{1}$ Karadeniz Teknik Üniversitesi, Farabi Hastanesi, Radyoloji Anabilim Dalı, Trabzon}

Künt travma sonrası, çoğunlukla yaralanan karın içi organ karaciğerdir. Karaciğer masif yaralanma yönetimi kompleks bir durumdur. Karaciğer cerrahisi sonrası gelişen özellikle proksimal biliyer duktus striktürlerinde perkütanöz transhepatik biliyer drenaj göz önünde bulundurulması gereken ilk yaklaşımdır. Acil servisimize grade $V$ karaciğer yaralanması olan, 27 yaşında bir kadın hasta transfer edildi. Hemodinamik olarak değişken olan hastaya sağ hepatektomi yapıldı. Cerrahi sonrası hasta, biliyer duktusda benign striktür ile başvurdu ve bu durum perkütanöz yaklaşımla tedavi edildi. Anahtar sözcükler: Benign biliyer striktür, karaciğer yaralanması; perkütanöz yaklaşım.

Ulus Travma Acil Cerrahi Derg 2017;22(5):44I-444 doi: 10.5505/tjtes.2017.52196 